\title{
Simulation of the behavior of reservoir for the use of rain water for agricultural use
}

\author{
Patrícia dos Santos Nascimento ${ }^{1}$; Eduardo Henrique Borges Cohim Silva ${ }^{2}$.
}

${ }^{1,2}$ Universidade Estadual de Feira de Santana (UEFS).

Email: patysnasc@gmail.com,edcohim@gmail.com

Received: February $21^{\text {th }}, 2017$

Accepted: May 16 $16^{\text {th }}, 2017$

Published: June $30^{\text {th }}, 2017$

Copyright $@ 2016$ by authors and Institute of Technology Galileo of Amazon (ITEGAM). This work is licensed under the Creative Commons Attribution International License (CC BY 4.0).

http://creativecommons.org/lic enses/by/4.0/ (c) (1) (3) Open Actes:

\section{ABS TRACT:}

The study objective was to simulate the behavior of a reservoir to capture and rainwater storage to enable the cultivation of beans in a household in the city of Serrinha, Ba. In the simulation of the reservoir 7 years a series of precipitation was used. The catchment area was adopted $200 \mathrm{~m}^{2}$; reservoir volume of 52,000 liters and $240 \mathrm{~m}^{2}$ planting area. In the analysis of the behavior and reliability of the model we used the bean crop. The results revealed that to meet the demand required by the bean throughout the development cycle with higher degree of confidence to $99 \%$ is possible. We conclude that the rainwater harvesting constitutes a viable alternative to meet the basic demand for beans for small households.

Keywords: irrigation, rain, storage.

\section{Simulação do comportamento de reservatório para aproveitamento de água da chuva para uso agrícola}

\section{RESUMO}

O Objetivo do estudo foi simular o comportamento de um reservatório para captação e armazenamento da água da chuva para viabilizar o cultivo de feijão num núcleo familiar no município de Serrinha, Ba. Na simulação do reservatório foi utilizada uma série de 7 anos de precipitação. A área de captação adotada foi $200 \mathrm{~m}^{2}$; volume do reservatório de 52 mil litros e área de plantio de $240 \mathrm{~m}^{2}$. Na análise do comportamento e confiabilidade do modelo utilizou -se a cultura do feijoeiro. Os resultados revelaram que é possível o atendimento da demanda requerida pelo feijão ao longo do ciclo de desenvolvimento com grau de confiança superior a $99 \%$. Conclui-se que a captação de águas pluviais constitui-se numa alternativa viável para atender a demanda básica de feijão para pequenos núcleos familiares.

Palavra-Chave: irrigação, chuva, armazenamento.

\section{INTRODUÇÃO}

A água é o recurso mais importante em todos os aspectos da vida, e sem a mesma seria inviável a sobrevivência humana. A manutenção deste recurso finito em padrões de quantidade e qualidade com o objetivo de atendimento aos seus múltiplos usos representa um desafio para a sociedade [1]. A disponibilidade de água de boa qualidade existente na natureza vem diminuindo gradativamente, em razão do crescimento populacional, da expansão das fronteiras agrícolas e da degradação do meio ambiente [2].

A precipitação da chuva é umas das etapas do ciclo hidrológico. De toda a água precipitada, parte escoa pela superfície do solo até chegar aos rios, lagos e ao oceano, parte retorna imediatamente para a atmosfera por evaporação e parte infiltra no solo, promovendo a recarga subterrânea [3].

Dentre as alternativas para otimização do uso dos recursos hídricos disponíveis tem se destacado o aproveitamento da água de chuva, uma técnica que além de contribuir com o armazenamento de água para diferentes usos a captação de água de chuva contribui fortemente na minimização dos picos de volumes nos leitos dos rios, pois, quando se reserva a água da chuva, ela deixa de cair diretamente no solo, diminuindo a quantidade de água do escoamento superficial evitando o transbordamento das redes pluviais municipais [4]. De acordo com [5], apesar de milenar a captação e utilização de água de chuva é uma tecnologia moderna quando associada a novos conceitos e técnicas construtivas e de segurança sanitária. 
O sistema de captação e armazenamento da água da chuva refere-se à tecnologia utilizada para coletar e armazenar água da chuva que passa por determinada superfície de captação (telhados, superfície terrestre, encostas íngremes, pisos ou áreas de rocha), usando instrumentos simples de armazenamento (potes, tanques e cisternas), bem como técnicas mais complexas (barragens subterrâneas, trincheiras, valas e poços de infiltração, entre outros). Os sistemas usados devem ser considerados três componentes principais, a saber, a superfície de captação, o dispositivo de coleta, e o sistema de armazenamento [6].

A escassez de recursos hídricos que assola a região semiárida do Nordeste brasileiro torna praticamente impossível a prática de uma agricultura voltada para a produção de excedentes alimentares e para a sobrevivência dos rebanhos bovinos, caprinos e ovinos, principal fonte de renda e reserva de poupança dos pequenos agricultores [7].

Nesse sentido, observa-se que a pesquisa agrícola é imprescindível ao propósito de se gerar tecnologia que sirva de base para propor formas de aumentar a rentabilidade dos produtores e, ao mesmo tempo, proporcionar o uso racional, conservação e recuperação dos recursos naturais.

Segundo [8], o Brasil é o segundo produtor mundial de feijão do gênero Phaseolus e o primeiro na espécie Phaseolus vulgaris. A importância dessa produção enfoca que o feijão, além de constituir um dos alimentos básicos da população brasileira, é um dos principais produtos fornecedores de proteína na dieta alimentar das classes sociais economicamente menos favorecidas. O feijão é um alimento quase obrigatório da população brasileira, devido ao seu valor protéico No Brasil estima-se que setenta e dois por cento de água utilizada seja designada a atividade agrícola, e devido a esse grande volume, vem-se discutindo questões de políticas alternativas para essa atividade [9].

A administração dos conflitos entre os diferentes usuários dos recursos hídricos pode ser realizada com uma visão de gestão integrada do uso, o controle e a conservação dos recursos hídricos [10].
A abordagem integrada do planejamento do uso e da gestão compartilhada dos recursos naturais é prática necessária e inadiável. É possível reduzir os conflitos da utilização dos recursos hídricos a um patamar mínimo, promovendo alternâncias espaciais ou de recurso utilizado para usos mais eficientes. Além disso, a vinculação do desenvolvimento social e econômico à proteção e à melhoria do meio ambiente pode contribuir decisivamente para $o$ atendimento dos objetivos do desenvolvimento sustentável [11].

Assim esta pesquisa objetivou simular o comportamento de um reservatório para captação e armazenamento da água da chuva para viabilizar o cultivo de feijão num núcleo familiar no município de Serrinha, Bahia.

\section{MATERIAIS E MÉTODOS}

Inicialmente foi realizada uma revisão de literatura sobre os parâmetros necessários para o dimensionamento de reservatório de acumulação pluvial para atender ao pleno desenvolvimento da cultura do feijão (Phaseolus vulgaris L.), considerando um núcleo familiar composto por 5 pessoas. Para a simulação do reservatório de captação de água foi selecionado o município de Serrinha-Ba, que apesar de estar locado no semiárido nordestino apresenta precipitações bem distribuídos ao longo do ano. As variáveis meteorológicas utilizadas para a determinação da demanda hídrica atmosférica do município foram disponibilizadas pelo CPETEC através dos dados diários de uma série histórica de 7 anos de observação.

Foi desenvolvida uma planilha eletrônica no software MS Excel, a qual se baseou no balanço hídrico climatológico diário para o dimensionamento da estrutura de captação e armazenamento das águas pluviais, de modo a suprir a demanda hídrica do cultivo agrícola. Na Figura 1, esta apresentada a concepção do modelo utilizado, o qual foi desenvolvido por [12].

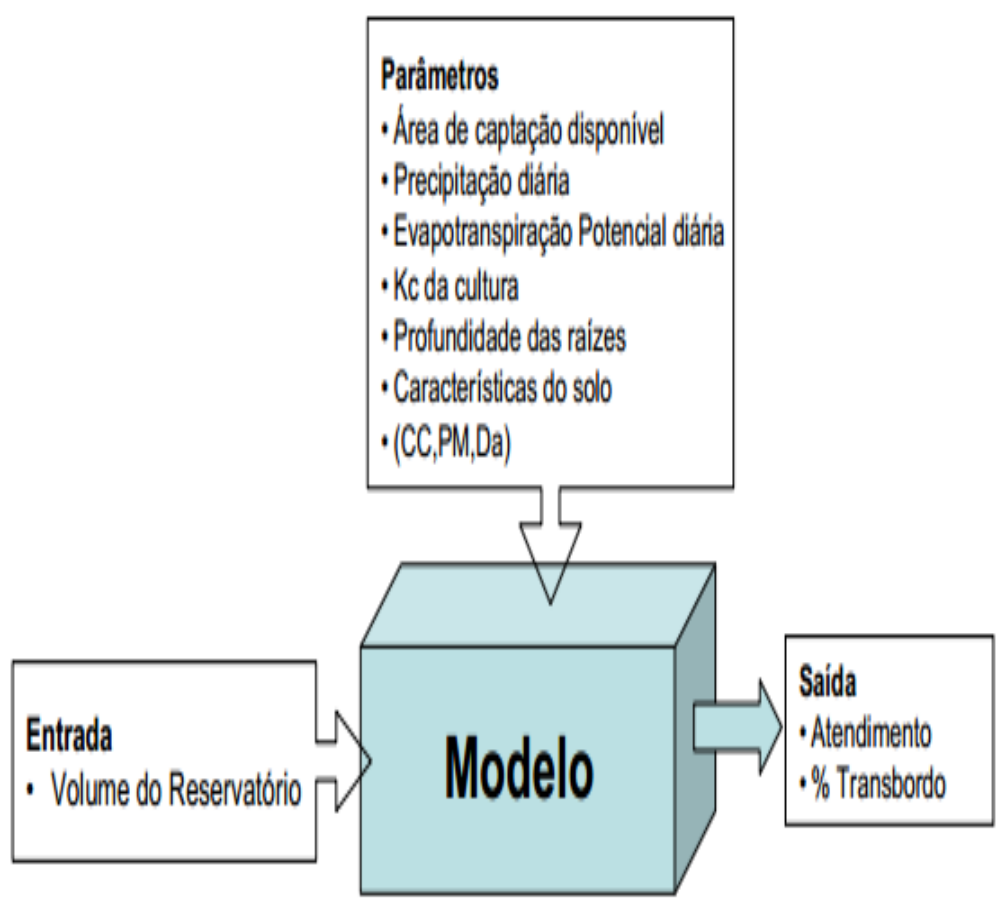

Figura 1: Esquema do modelo para dimensionamento de reservatório pluvial.

Fonte: Autores, (2016). 
Para o dimensionamento do reservatório para captação de água pluvial foram utilizados os seguintes parâmetros: regime de chuvas local, área de captação disponível, demanda de recursos hídricos e o nível de risco aceitável. O tipo de consumo a que será destinada a água de chuva e a existência de outras fontes para suprimento deste, implicará no grau de risco aceitável ao esvaziamento do reservatório.

O dimensionamento utilizado baseou-se no modelo proposto por [13], utilizando o Modelo Comportamental, definindo um algoritmo mais generalizado para a operação do reservatório. [14] e [13] identificaram dois algoritmos fundamentais para o modelo comportamental. Um algoritmo descreve a regra de operação de reservatório de produção depois do enchimento (PDE) e o outro descreve a regra de operação do reservatório de produção antes do enchimento (PAE), conforme equações abaixo:

$$
\begin{gathered}
Y_{t}=\min \left\{\begin{array}{c}
D_{t} \\
V_{t-1}+\theta Q_{t}
\end{array}\right. \\
V_{t}=\min \left\{\begin{array}{c}
\left(V_{t-1}+Q_{t}-\theta Y_{t}\right)-(1-\theta) Y_{t} \\
S-(1-\theta) Y_{t}
\end{array}\right.
\end{gathered}
$$

Onde: $\theta$ é um parâmetro entre 0 e 1 . Utilizando $\theta=0$, o algoritmo descreve a regra de operação de reservatório de produção depois do enchimento (PDE). Quando $\theta=1$ descreve a regra de operação do reservatório de produção antes do enchimento (PAE), utilizando também as seguintes variáveis.

$\mathrm{Y}=$ Produção de chuva no sistema, responsável por suprir a demanda $\left(\mathrm{m}^{3}\right)$;

$\mathrm{D}=$ Demanda $\left(\mathrm{m}^{3}\right)$;

$\mathrm{V}=$ Volume de chuva no reservatório de armazenamento $\left(\mathrm{m}^{3}\right)$;

$\mathrm{Q}=$ Volume total de chuva coletado pelo sistema $\left(\mathrm{m}^{3}\right)$;

$\mathrm{S}=$ Volume do reservatório de armazenamento $\left(\mathrm{m}^{3}\right)$.

\section{RESULTADOS E DISCUSSÃO}

Para a simulação do reservatório foi adotada inicialmente uma capacidade de água total disponível no solo de $79 \mathrm{~mm}$, em função das características físico-hídricas do solo simulado associada à profundidade efetiva do feijoeiro. De posse da demanda atmosférica do feijoeiro, expressa pela evapotranspiração da cultura simulou-se o percentual de atendimento do reservatório durante o período em análise. De acordo com [15], para o desenvolvimento de uma região, há necessidade de tecnologias, as quais devem ser acessíveis e possíveis de serem adotadas pelos produtores, promovendo o aumento de produtividade, com o mínimo risco ao meio ambiente.

A expressão do atendimento da demanda hídrica da área cultivada associada a contribuição direta da precipitação sobre a cultura quando esta ocorrer. Assim, no momento da precipitação tanto os cultivos quanto o reservatório estariam sendo supridos com recursos hídricos, dispensando o uso do reservatório quando a precipitação for igual ou superior a lâmina de reposição (79 $\mathrm{mm}$ ), aumentando assimo potencial de armazenamento deste.

A simulação do comportamento do reservatório para o município de Serrinha considerando um período de 7 anos, revelou que a utilização de uma área de plantio de $240 \mathrm{~m}^{2}$ viabilizaria a condução do feijoeiro com $99 \%$ de confiabilidade de atendimento da demanda.

De acordo com [16], com prognóstico de períodos de seca e se conhecendo a variação temporal e espacial das precipitações, é possível um melhor planejamento da época de plantio e melhor adequação ao uso da irrigação.

A área de cultivo simulada de $240 \mathrm{~m}^{2}$ é suficiente para a condução de até 3 ciclos regulares de produção do feijão durante o ano, considerando o ciclo médio da cultura de 120 dias, tal produção atenderia a demanda de núcleo familiar constituído por 5 pessoas, uma vez que o rendimento médio, por hectare, varia de $2,7 \mathrm{t}$ ha-1 a 3,0 t ha-1 [18]. Estudos que visavam o abastecimento de uma família de até 5 pessoas considerando uma cisterna com volume de armazenamento de 16 mil litros de água, indicaram que esse volume seria suficiente para o abastecimento por um período de até 8 meses [18].

A cultura do feijão foi selecionada por constituir um dos mais importantes componentes da dieta alimentar do brasileiro.
Segundo informações da [19], as Américas respondem por $38,5 \%$ do consumo mundial, seguidas pela Ásia $(37,8 \%)$, África $(17,9 \%)$, Europa $(3,3 \%)$ e Oceania $(0,1 \%)$. Além de seu papel fundamental como fonte protéica de origem vegetal, além de ser um dos principais constituintes da cesta básica nacional, o feijão é produto merecedor de especial atenção dos governantes, da pesquisa e de toda sua cadeia produtiva [20].

A simulação do reservatório de captação de água de chuva mostrou-se eficiente constituindo-se num acréscimo na oferta de água para vários fins, liberando os recursos hídricos dis poníveis para utilização em outros usos onde existe uma maior exigência da qualidade da água, tais como o abastecimento humano.

\section{CONCLUSÕES}

A partir das simulações efetuadas e da revisão bibliográfica, conclui-se que a captação e utilização de águas pluviais para a irrigação, quando associada ao dimensionamento criterioso do sistema de captação, coleta e reservarão dos recursos hídricos, considerando as demandas hídricas dos cultivos agrícolas constitui-se numa alternativa viável para o atendimento das demandas hídricas do feijoeiro para pequenos núcleos familiares, além de diminuir a pressão nos mananciais e permitir o direcionamento das águas pluviais para atendimento à consumos mais nobres, para uma parcela maior da população.

\section{REFERÊNCIAS}

[1] Santos, E. H. M.; Griebeler, N. P.; Oliveira, L. F. C. Relação entre uso do solo e comportamento hidrológico na Bacia Hidrográfica do Ribeirão João Leite. Revista Brasileira de Engenharia Agrícola e Ambiental, v.14, n.8, p.826-834, 2010.

[2] Medeiros, S.; Soares, A. A.; Ramos, M. M.; Mantovani, E. C.; Souza, J. A. A. Avaliação do manejo de irrigação no Perímetro Irrigado de Pirapora, MG. Revista Brasileira de Engenharia Agrícola e Ambiental, Campina Grande, v. 7, n. 1, p.80-84, 2003. 
[3] Garcez, L. N. Elementos de engenharia hidráulica e sanitária. 2. ed. São Paulo: Edgard Blücher, 1974.

[4] Dornelles, F. Aproveitamento de água de chuva no meio urbano e seu efeito na drenagem pluvial. Programa de PósGraduação em Recursos Hídricos e Saneamento Ambiental. Universidade Federal do Rio Grande do Sul, Porto Alegre. 224f, 2012.

[5] Andrade Neto, C. O. de. Proteção Sanitária das Cisternas Rurais. In: Anais do XI Simpósio Luso-brasileiro de Engenharia Sanitária e Ambiental, Natal, 2004. Natal: ABES/APESB/APRH. 2004.

[6] Lima, J. C. A. L. de. Avaliação do desempenho de dispositivo de desvio das primeiras águas de chuva utilizado em cisternas no semiárido pernambucano. Programa de PósGraduação em Engenharia Civil. Universidade Federal de Pernambuco, Recife. 101f, 2012.

[7] Cavalcanti1, N. de B.; Oliveira, C. A. V. de.; Brito, L. T. de L.; Resende, G. M. Avaliação do uso de técnicas de captação de água de chuva na região semi-árida do Nordeste Brasileiro. Revista Brasileira de Engenharia Agrícola e Ambiental, v.3, n.3, p.403-407, 1999.

[8] Yokoyama, Lidia Pacheco. Tendências de mercado e alternativas de comercialização do feijão. Embrapa Arroz e Feijão, 2002.

[9] AGENCIA NACIONAL DE AGUAS. Irrigação é a finalidade mais outorgada de 2012. Brasília/DF, 2013. Disponível

em:

$<$ http://www2.ana.gov.br/Paginas/imprensa/noticia.aspx?id_notici $\mathrm{a}=11655$ >. Acesso em 08 julho 2016.

[10] Tucci, C. E. M.; Hespanhol, I.; Cordeiro Netto, O. M. Gestão da Água no Brasil. Brasília, DF: UNESCO, 2001. 153 p.

[11] Anjos, E. F. S. Os comitês de bacia hidrográfica: lições da experiência de Minas Gerais. Brasília, DF: UnB, 2003. 139 f. Dissertação (Mestrado em Desenvolvimento Sustentável) -
Centro de Desenvolvimento Sustentável, Universidade de Brasília, Brasília.

[12] Cohim, Eduardo; Garcia, P.A; Silva, A; Kiperstok, Asher. Dimensionamento de reservatório para captação direta de água de chuva para irrigação. In: $6^{\circ}$ Simpósio brasileiro de captação e manejo de água de chuva. Belo Horizonte, 2007.

[13] Fewkes, A. The use of rainwater for WC flushing: the fieldtesting of a collection system. Building and Environment, v. 34, n. 9, p. 765-772, 1999.

[14] Jenkins, Henry. Cultura da convergência. Aleph, 2015.

[15] Paz, V.P.S.; Teodoro, R.E.F.; Mendonça, F.C. Recursos hídricos, agricultura irrigada e meio ambiente. Revista Brasileira Engenharia Agrícola e Ambiental, Campina Grande, v.4, n.3, p.465-473, 2000 .

[16] Souza, S. A. V. Programa computacional para simulação da ocorrência de veranicos e queda de produção. Piracicaba: ESALQ/USP, 1999. 124p. Tese Doutorado.

[17] Silva, O.F. da; Faria, L.C. de; Melo, L.C.; Del Peloso, M.J. Sistemas e custos de produção de feijoeiro comum (Phaseolus vulgaris L.) em diferentes épocas e regiões de cultivo. Santo Antônio de Goiás: Embrapa Arroz e Feijão, 2004, 40 p. (Documentos, 168).

[18] Articulação do Semiárido Brasileiro. Cisternas nas escolas. Recife, 2013. Disponível em: $<$ http://www.asabrasil.org.br/Portal/Informacoes.asp?COD_MEN $\mathrm{U}=5622 \& \mathrm{WORDKEY}=$ Cist erna $>$. Acessado em 18 maio 2015.

[19] FAO. Statistics Division 2010. Disponível em: <www.faostat.fao.org>.Acesso em: 13 Ago. 2016.

[20] Ramos Junior, E. U.; Lemos, L. B.; Silva, T. R. B. da. Componentes da produção, produtividade de grãos e características tecnológicas de cultivares de feijão. Bragantia. Campinas ,v. 64, n. 1, p. 75-82, 2005. 